\title{
Interaction between a 3D collagen matrix used for periodontal soft tissue regeneration and T-lymphocytes: An in vitro pilot study
}

\author{
DARIAN RUSU ${ }^{1}$, MARIUS BOARIU $^{2}$, ȘTEFAN-IOAN STRATUL $^{1}$, FLORINA BOJIN $^{3}$, VIRGIL PAUNESCU ${ }^{3}$, \\ HORIA CALNICEANU ${ }^{1}$, PETRA SURLIN ${ }^{4}$, ALEXANDRA ROMAN $^{5}$, ȘTEFAN MILICESCU $^{6}$, COSTIN CARUNTU $^{7}$, \\ ANDREEA DIDILESCU ${ }^{8}$, NELA-PUSA GAJE ${ }^{9}$ and BOGDAN CALENIC ${ }^{10}$ \\ Departments of ${ }^{1}$ Periodontology and ${ }^{2}$ Restorative Dentistry and Endodontics, 'Victor Babes' University of Medicine and \\ Pharmacy, 300141 Timisoara; ${ }^{3}$ Department of Physiology, 'Victor Babes' University of Medicine and Pharmacy, \\ 300230 Timisoara; ${ }^{4}$ Department of Periodontology, University of Medicine and Pharmacy, 200349 Craiova; \\ ${ }^{5}$ Department of Periodontology, 'Iuliu Hatieganu' University of Medicine and Pharmacy, 400012 Cluj-Napoca; \\ ${ }^{6}$ Department of Fixed Prosthodontics, 'Carol Davila' University of Medicine and Pharmacy; ${ }^{7}$ Department of \\ Physiology, Faculty of Midwifery and Nursing, 'Carol Davila' University of Medicine and Pharmacy; ${ }^{8}$ Department of \\ Embryology, 'Carol Davila' University of Medicine and Pharmacy, 020021 Bucharest; ${ }^{9}$ Department of Histology, \\ 'Victor Babes' University of Medicine and Pharmacy, 300230 Timisoara; ${ }^{10}$ Department of Biochemistry, Faculty of \\ Dental Medicine, 'Carol Davila' University of Medicine and Pharmacy, 020021 Bucharest, Romania
}

Received August 13, 2018; Accepted September 24, 2018

DOI: 10.3892/etm.2018.6979

\begin{abstract}
Previous experimental models showed that activation of the immune system, particularly $\mathrm{T}$ cells, is required for optimal healing following wounds or surgery in the oral cavity. Therefore, studies to explore the interactions between the immune system and the collagen matrix are mandated. The specific aim of the present study was to analyze the interactions between $\mathrm{T}$ lymphocytes and a resorbable threedimensional (3D) collagen matrix routinely used for soft tissue regeneration during periodontal surgery. Peripheral venous blood samples were collected from five patients. Following Ficoll-Paque separation, mononuclear cells were grown on fully resorbable 3D collagen matrices for 5 days. Lymphocytes were analyzed by flow cytometry for different surface markers, including CD4, CD8, CD38 and CD69. Cell viability and late apoptosis/necrosis were assessed in each group using an apoptosis assay based on Annexin V/propidium iodide staining. After 5 days in contact with the collagen matrix, the T cells expressed different surface markers. The overall T cell population increased significantly in the collagen matrix group compared to the respective controls $(31.9 \pm 6.5$ vs. $38.7 \pm 3.8 \%)$. CD8 and CD69 also increased significantly compared to
\end{abstract}

Correspondence to: Professor Marius Boariu, Department of Restorative Dentistry and Endodontics, 'Victor Babes' University of Medicine and Pharmacy, Bulevardul Revolutiei din 1989, nr. 9, 300141 Timisoara, Romania

E-mail: boarium@yahoo.com

Key words: T-lymphocytes, oral mucosa, collagen matrix, apoptosis, wound healing their controls (CD69: $19.7 \pm 3.0$ vs. $27.1 \pm 4.5 \%$ for collagen vs. control groups). At the same time, CD4 and CD38 expression was similar in both groups. Viability and apoptosis/ necrosis were also identical in the samples and controls. These results show that the interaction between the collagen matrix and the immune cells stimulated activation of $\mathrm{T}$ cells and did not impair the healing process.

\section{Introduction}

Keratinized gingiva extends from the gingival margin to the muco-gingival junction and is a specialized mucosa that maintains the underlying osseous stability and a healthy dentogingival junction (1). Recently in clinical practice, soft tissue augmentation procedures have received increasing attention due to their benefits. Thus, gingival augmentation improves patient comfort, prevents recession of the gingiva, and facilitates plaque control of teeth where plaque accumulation leads to inflammation of the surrounding tissues and mucosal recession $(2,3)$. On the other hand, the use of collagen matrices instead of connective tissue grafts for root coverage results in good healing and significantly reduced recession (4). Various surgical methods and materials have been described in the literature, but the most frequent is the repositioned flap and application of an autogenous free gingival graft or subepithelial connective tissue graft harvested from the palatal mucosa (5). Acellular dermal matrix grafts and human-derived dermal substitutes were initially proposed as viable alternatives $(6,7)$. A two-layer recombinant xenogeneic collagen matrix and a porcine-derived dermal matrix have been used more recently, with good results for augmenting keratinized tissue and recession coverage procedures in teeth and dental implants $(8,9)$.

Wound healing following periodontal surgery and placement of the collagen matrix is a complex process, 
where a multitude of factors, including the immune system, interact (10). Many factors can modulate the regeneration outcome of the oral mucosa once the immune system contacts the collagen matrix. Among these, $\mathrm{T}$ cells are one of the most important immune cellular effectors, and their role in wound healing has been described in detail in the oral cavity as well as other organs and tissues (11-13). T cells accumulate in the skin and oral mucosa early after a wound occurs or is created, and specific ablation of these cells results in delayed wound re-epithelialization and kinetics of wound closure (14).

However, the molecular interactions between these matrices, the surrounding tissues, and their cellular components, such as keratinocytes and immune cells, have not been fully explored. In a previous study, we showed that resorbable collagen matrices stimulate the healing process post-surgery, allowing the formation of new oral epithelia, while being incompletely integrated into the newly formed soft tissue (15). To the best of our knowledge there are no studies that explored the interactions between a resorbable three-dimensional (3D) collagen matrix and T cells. Previous experimental models showed that activation of the immune system, particularly $\mathrm{T}$ cells, is required for optimal healing following wounds (16) or surgery in the oral cavity. Therefore, studies to explore the interactions between the immune system and the collagen matrix are mandated.

The aim of the present study was to investigate the effect of a resorbable $3 \mathrm{D}$ collagen matrix on activation of autologous primary T cells and activation-induced cell death in these cells.

\section{Materials and methods}

Patient selection. The present study was designed as a pilot study of five patients selected from subjects under treatment at the Department of Periodontology of the Victor Babes University of Medicine and Pharmacy, Timisoara, Romania. All patients met several inclusion criteria: Young adults with no local or systemic diseases and not taking any medication over the past 6 months prior to the study. The exclusion criteria included smokers, pregnancy, chronic or acute inflammatory disease or infection, past alcohol abuse, active periodontal disease, and allergies. The protocol and patient informed consent process were approved by the Commission of Research Ethics of the 'Victor Babes' University of Medicine and Pharmacy of Timisoara, Romania (Timisoara, Romania), and written informed consent was obtained from all patients.

Isolation of mononuclear cells from peripheral venous blood. Samples of peripheral venous blood were collected from subjects in anticoagulant (heparin 15,000 IU/5 ml; Biochemie $\mathrm{GmbH}$, Kundl, Austria). The peripheral blood mononuclear cells (PBMCs) were separated from peripheral blood by centrifugation on a Ficoll-Paque ${ }^{\mathrm{TM}}$ Plus (GE Healthcare Bio-Sciences AB, Uppsala, Sweden) gradient. The blood samples were transferred to $16 \mathrm{ml}$ Falcon (Becton-Dickinson, Brea, CA, USA) sterile tubes and diluted at 1:1 with PBS. Each sample was transferred to a $50 \mathrm{ml}$ Falcon sterile tube with Ficoll-Paque, so that the ratio of the diluted sample: Ficoll was 1:1. The transfer of diluted biological samples over the Ficoll layer was gentle, without mixing the two components, allowing the formation of a density gradient. The samples were centrifuged at $400 \mathrm{x}$ g for $30 \mathrm{~min}$. After centrifugation, the ring of mononuclear cells at the interface of the components was harvested and moved to a sterile tube. This step was followed by two successive washes with PBS and consecutive centrifugations at $100 \mathrm{x}$ g for $10 \mathrm{~min}$. After the second centrifugation, the supernatant was removed, and the cell pellet was used for further analysis, or frozen at $-80^{\circ} \mathrm{C}$ (or $-196^{\circ} \mathrm{C}$ ) and kept for further investigation.

$3 D$ collagen matrix. PBMCs were seeded on a fully resorbable $3 \mathrm{D}$ collagen matrix specially designed for soft tissue regeneration (Geistlich Mucograft ${ }^{\circledR}$; Geistlich Pharma AG, Wolhusen, Switzerland). This collagen matrix is routinely used for various periodontal surgical procedures in the Department of Periodontology of the Victor Babes University of Medicine and Pharmacy.

In vitro growth of PBMCs. The PBMCs were cultured for $48 \mathrm{~h}$ in $\mathrm{T}$ cell expansion Stemline media (Sigma-Aldrich; Merck KGaA; Darmstadt, Germany), supplemented, as specified by the producer, with $10 \mathrm{ml}$ of $200 \mathrm{mM} \mathrm{L}$-glutamine $/ 500 \mathrm{ml}$ medium to increase the T cell population. After $48 \mathrm{~h}$ of in vitro culture, the cells $\left(1 \times 10^{5} \mathrm{~T}\right.$ cells $\left./ \mathrm{mm}^{3}\right)$ were placed in contact with the $3 \mathrm{D}$ collagen matrix and were transferred to 24-well plates. A comparative analysis was performed between the cells in contact with the $3 \mathrm{D}$ collagen matrix and untreated cells.

Viability tests - Annexin V/propidium iodide (PI). The Annexin V/PI method was used in order to detect late apoptosis. This assay measures changes in the plasma membrane using Annexin V labeled with a fluorochrome, which binds specifically to phosphatidylserine normally present on the internal face of the plasma membrane. In accordance with the manufacturer's recommendations, $1 \times 10^{6}$ cells were counted using a hemocytometer, washed in $1 \mathrm{X}$ Annexin $\mathrm{V}$ Binding Buffer (BD Pharmingen, San Diego, CA, USA), centrifuged at $300 \mathrm{x} \mathrm{g}$ for $10 \mathrm{~min}$, resuspended in the same solution, and incubated in $10 \mathrm{ml}$ of Annexin V-FITC for $15 \mathrm{~min}$ in the dark. After washing the cells with $1 \mathrm{ml}$ of specific buffer followed by centrifugation, the cell pellet was resuspended in $500 \mu \mathrm{l}$ of binding buffer, and a $1 \mu \mathrm{g} / \mathrm{ml}$ PI solution was added before the flow cytometric analysis. Data acquisition was performed with FACSCalibur flow cytometer and the data analysis was performed using Flow Software 2.5 (Becton-Dickinson).

Immunophenotyping analysis of T cells by flow cytometry. A lymphocyte immunophenotyping analysis was carried out for the lymphocytes cultured in the main culture medium which represented the control cells, as well as for lymphocytes that were in contact with the collagen matrix for 5 days which represented our target cells. Surface markers were evaluated by flow cytometry after preparing the cells for this purpose. The cells $\left(10^{5}\right.$ cells $\left./ \mathrm{ml}\right)$ were washed in PBS, resuspended in PBS, and incubated for $30 \mathrm{~min}$ in the dark with fluorochromeconjugated monoclonal antibodies using the manufacturer's recommended dilutions. After washing with a specific solution (Cell Wash Solution; BD Biosciences, San Diego, CA, USA), the cells were resuspended in $500 \mu \mathrm{l}$ Cell Wash and 

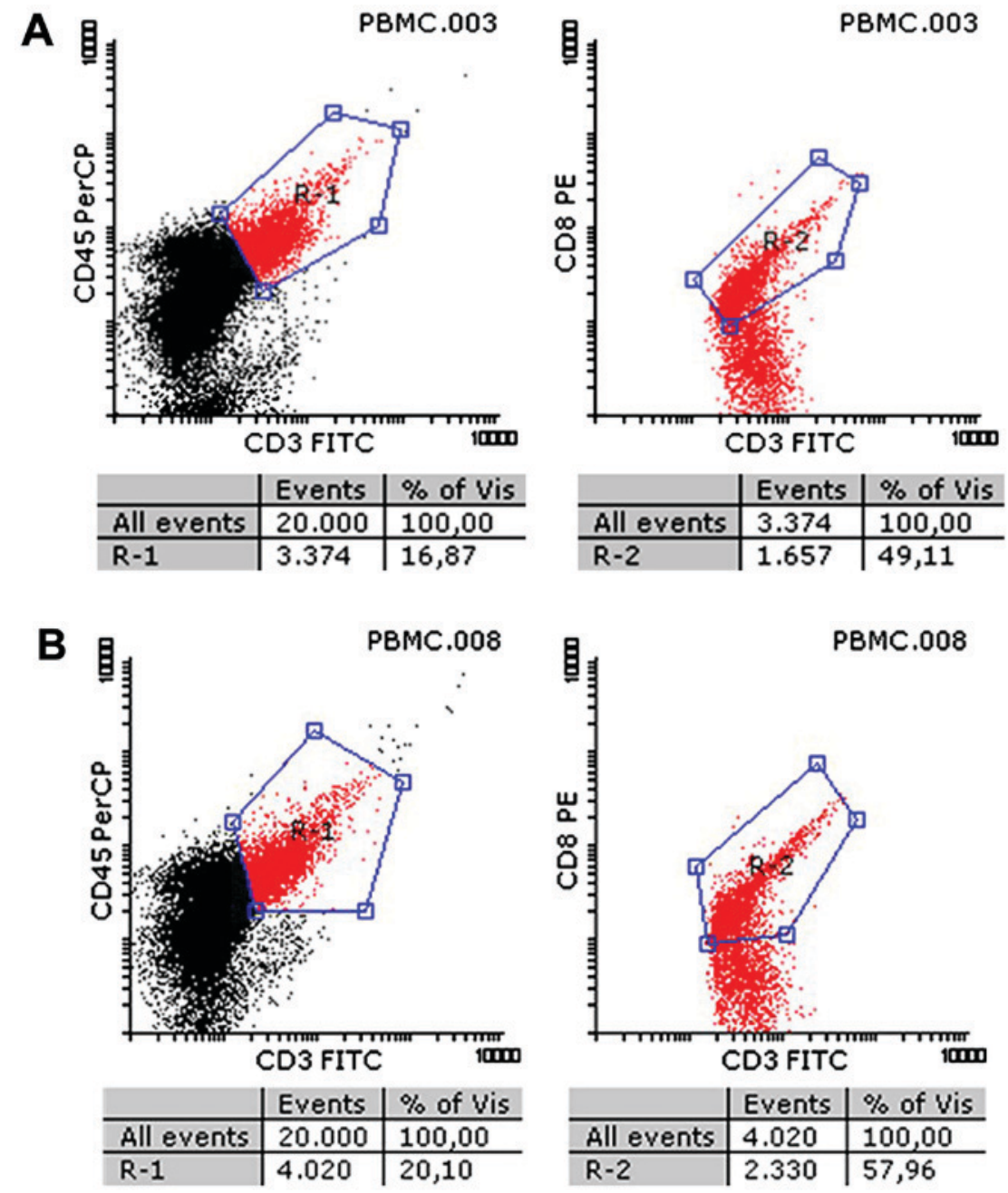

Figure 1. Representative dot plots of unstimulated $\mathrm{T}$ cells (control) and collagen matrix-activated $\mathrm{T}$ cells. A representative dot plot for the unstimulated $\mathrm{T}$ cells (control) is shown in (A), and a representative dot plot for the collagen matrix-activated T cells is shown in (B), displaying an increase in the percentage of cytotoxic T cells.

analyzed with a FACSCalibur flow cytometer. Data were acquired using CellQuest Pro software (Becton-Dickinson), and the data analysis was performed using Flow Software 2.5. The primary antibodies conjugated with fluorochromes (BD Pharmingen) used for immunophenotyping characterization of the PBMCs were: CD3 (FITC)/CD16 + 56 (PE)/CD45 (PerCP)/CD19 (APC); CD3 (FITC)/CD8 (PE)/CD45 (PerCP)/ CD4 (APC); CD25 (FITC)/CD38 (PE); and CD69 (FITC)/ CD166 (PE).

Statistical analysis. All data are representative of three separate experiments. The statistical analysis was performed using the PASW Statistics 18.0 software (SPSS Inc., Chicago, IL, USA). The paired t-test was used to analyze the differences between the two groups. P-values $<0.05$ were considered to indicate statistically significant differences.

\section{Results and Discussion}

Comparative immunophenotyping analysis between unstimulated T cells (control) and collagen matrix-activated T cells. A comparative analysis was performed between cells in contact with the 3D collagen matrix and a control group of cells. As shown in Fig. 1 for $\mathrm{CD}^{+}$and in Fig. 3 for $\mathrm{CD}^{+}$, both cytotoxic $\mathrm{T}$ cell groups were increased significantly due to contact with the collagen matrix, compared to lymphocytes cultured in growth medium. Growth was seen in all samples, regardless of the initial immune status of the subject from which the blood sample was taken. Thus, the flow cytometry analysis showed values of $31.9 \pm 6.5$ vs. $38.7 \pm 3.8 \%$ for $\mathrm{T}$ cells in the control vs. collagen samples, respectively.

As illustrated in Figs. 2 and 3, the CD69 surface marker increased significantly on the surface of T cells in contact with the collagen matrix $(19.7 \pm 3.0$ vs. $27.1 \pm 4.5 \%$ for control and collagen sample group, respectively).

The present results showed inter-individual variations in expression of CD38 surface marker, but $>50 \%$ of the samples demonstrated decreased expression during contact of lymphocytes with the collagen matrix $(50.3 \pm 3.0$ vs. $46.8 \pm 9.1 \%$ for controls and collagen samples, respectively; P $>0.05$; no statistical significance) (Fig. 3).

At the same time, CD8 increased significantly $(20.7 \pm 5.5$ vs. $30.7 \pm 12.1 \%$ in controls vs. collagen samples; $\mathrm{P}<0.05$ ), but no difference was found in the CD4 lymphocytes (7.4 \pm 2.2 vs. $7.1 \pm 3.3 \%$; P>0.05). Both CD4 and CD8 cells are usually found in the wound bed at all stages of the wound 

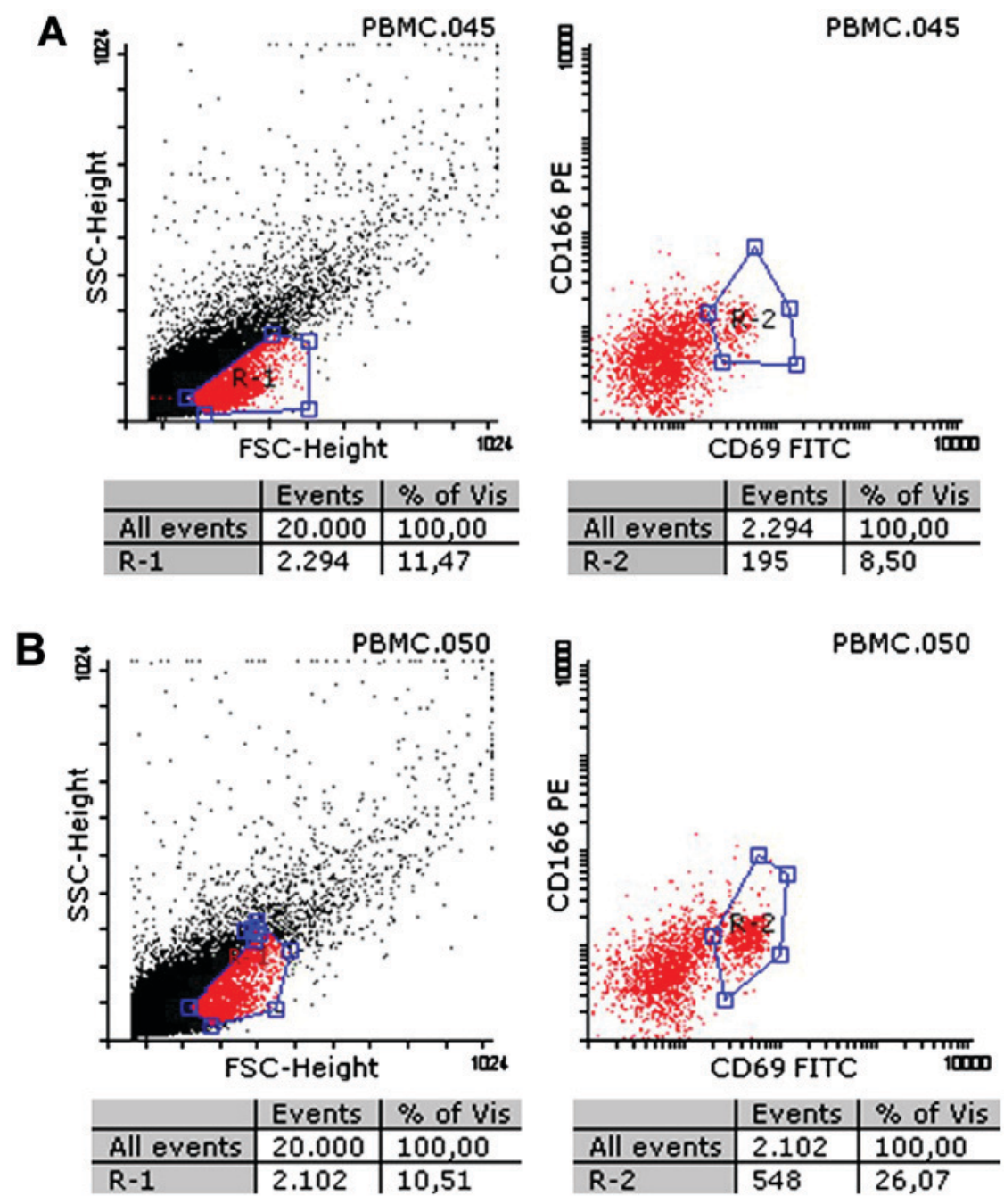

Figure 2. Representative dot plots for unstimulated T cells (control) and collagen matrix-activated T cells. A representative dot plot for the unstimulated T cells (control) is shown in (A), and a representative dot plot for the collagen matrix-activated T cells is shown in (B), displaying surface modifications of the CD69 activation marker.

healing process and are particularly involved in late stages of inflammation and early stages of tissue remodeling and proliferation.

Apoptosis and viability levels following T cell contact with the $3 D$ collagen matrix. As shown in Fig. 4, the 3D matrix induced no significant apoptotic cell death in T cells, compared to their respective controls. Moreover, the percentages of viable and dead cells were similar in both samples. A comparative analysis was performed between the cells in contact with the $3 \mathrm{D}$ collagen matrix and the control group cells (viable cells: $81.2 \pm 11.1$ vs. $78.5 \pm 13.9 \%$ in the control vs. collagen groups; $\mathrm{P}<0.05)$, whereas necrotic/late apoptotic cells were $18.5 \pm 11.1$ vs. $21.2 \pm 13.9 \%$ in the control vs. collagen groups, respectively $(\mathrm{P}<0.05)$.

Over the past decades, complete regeneration of the oral mucosa following surgery has been the focus of intense exploratory research. Allograft materials, such as acellular dermal matrix grafts, have been used as alternatives to avoid morbidity at the donor site. However, the complex interactions between the immune system and the artificial biomaterials used for oral soft tissue regeneration have not been thoroughly studied. The specific aim of the present study was to analyze for the first time the interactions between a resorbable 3D collagen matrix used for oral soft tissue regeneration and T cells, one of the most important immune players in the inflammatory microenvironment following oral soft tissue regenerative surgical procedures.

Apoptosis and migration of keratinocytes are vital for wound repair, and the $\mathrm{T}$ cells were demonstrated to ameliorate the wound-healing condition by increasing keratinocyte migration and proliferation and decreasing apoptosis of keratinocytes. More specifically, several subsets of T cells promote wound healing, which is a critical and complex process that occurs in the skin and other barrier sites. Activation of $\mathrm{T}$ cells at the injury site initiates massive infiltration of the wound with $\alpha \beta$ T cells that likely facilitate the transition from the inflammatory to the proliferative phase of healing, and defects in dermal $\gamma \delta$ T cells may be an important mechanism underlying delayed wound healing (17). A crucial role has been demonstrated for CD100-plexin B2 interactions in the wound healing response mediated by murine $\gamma \delta \mathrm{T}$ cells and in the $\mathrm{T}$ cell morphological changes associated with this process (18). $\mathrm{T}$ cell receptor ligands are not constitutively 


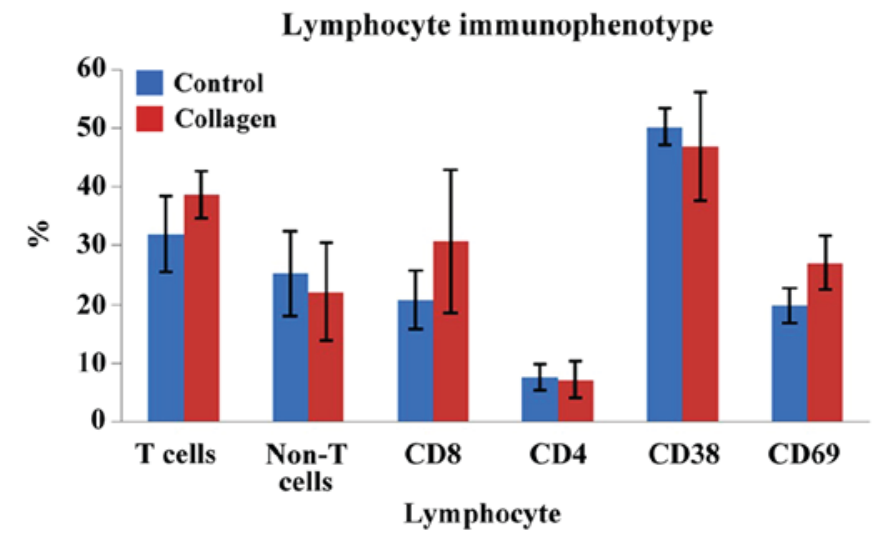

Figure 3. Lymphocyte immunophenotypes: $\mathrm{T}$ and non-T cells were immunophenotyped. The unstimulated $\mathrm{T}$ cells were compared to collagen matrix-activated T cells following 5 days of incubation. ${ }^{*} \mathrm{P}<0.05$.

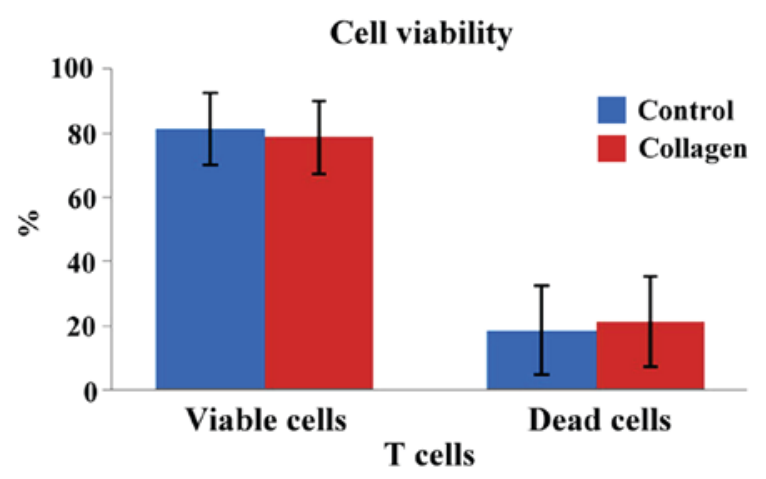

Figure 4. Lymphocyte viability: The viability of unstimulated $\mathrm{T}$ cells expressed as percentage of total cells, was compared to the viability of collagen matrix-activated $\mathrm{T}$ cells. Cells in late stages of apoptosis of necrosis were included in the cell death/cellular death levels.

expressed in healthy tissues but are rapidly upregulated following wounding of keratinocytes bordering wound edges. Ligand expression is tightly regulated, with down-modulation following T cell activation. Early inhibition of T cell receptorligand interactions delays wound repair in vivo, highlighting T cells as rapid responders to injury (19).

The results of this study show that the $\mathrm{T}$ cell population increased significantly when exposed to 5-day incubation with the selected collagen matrix compared to cultured lymphocytes. Stimulating the overall $\mathrm{T}$ cell population suggests that the immune system's effector cell subsets are activated when in contact with the collagen scaffold. This increase was detected in all analyzed samples, with no connection with the initial immune status of the patient from which the sample was collected. We infer that the efficiency of tissue repair may be increased.

CD69 is a cell activation antigen present on active immune system cells in the very early stage of the lymphocyte activation process $(20,21)$. Lymphocytes usually have very low levels of CD69, but nearly all bone-marrow derived cells express the marker within the first 1-3 $\mathrm{h}$ following activation. Once upregulated, CD69 affects T cell differentiation and modulates the inflammatory response. Our data show that the CD69 surface marker increased significantly on cells in contact with the collagen matrix in all five samples, suggesting that the matrix initiates the appropriate immune response needed for tissue repair.

CD38 is another cell surface marker present on T cells and is responsible for cellular adhesion, migration, and local angiogenesis $(22,23)$. The marker is usually expressed during inflammatory processes and appears later in the wound healing process. In this study, CD38 levels decreased slightly but not significantly in the $\mathrm{T}$ cell group exposed to the collagen matrix compared to the controls. The marker displayed variations between patients, but the finding that expression was similar in both groups suggests that longer incubation times are needed for this marker to be significantly expressed. Future studies are necessary to assess the expression of CD38 on the T cell surface following exposure to collagen.

Our study also analyzed CD4 and CD8 as two key surface markers of the inflammatory process of wound healing. These markers are present in the wound at all four stages of wound healing and have their highest levels during the early phase of proliferation and the late phase of wound inflammation (24,25). A decreased concentration of CD8 T cells and CD4 $\mathrm{T}$ cells can thus be associated with impaired or delayed wound healing. Our results show that CD8 increased significantly in the collagen sample cells, whereas CD4 levels were similar with the controls.

Annexin $\mathrm{V}$ is a $36 \mathrm{kDa}$ protein with a high affinity for phosphatidylserine, which is located on the cytoplasmic surface of the cell membrane. During execution of the apoptotic program, phosphatidylserine is externalized, and the cells become rapidly positive for Annexin V $(26,27)$. Translocation of phosphatidylserine occurs on the external surface membrane during apoptosis and phosphatidylserine is exposed to the outside as the cell membrane is destroyed during necrosis and becomes a trigger for activation of macrophages. This phenomenon is also present in activated platelets, during mast cell degranulation, and in several erythrocyte abnormalities. In the presence of calcium ions, Annexin V binds with high affinity to phosphatidylserine exposed by apoptotic cells. The labeling technique using Annexin V conjugated with fluorochrome was developed to detect and identify apoptotic cell and dead T cells (28). A viability marker (PI) was used distinguish apoptotic cells from cells with a permeabilized plasma membrane during late non-apoptotic death, so that only apoptotic cells appeared positive for Annexin V, and double positive cells (Annexin $\mathrm{V}^{+} / \mathrm{PI}^{+}$) were eliminated from the statistics. Apoptotic cells are detected by staining with Annexin V, dead cells are identified by Annexin V and PI, while the viable cells cannot be detected by any of these markers (29). Our present results show that the selected $3 \mathrm{D}$ collagen matrix does not include $\mathrm{T}$ cells in early or late apoptosis. The percentage of viable cells was the same in the samples and controls. These findings demonstrate that the collagen matrix is nontoxic to immune system cells and does not hinder the healing process following periodontal surgery for soft tissue regeneration. A further study should address the compatibility of the collagen matrix with another important component of the healing process, the cells belonging to the epithelial compartment, namely epithelial cells. It is known that prolonged healing times or chronic inflammation can initiate or potentiate tumor processes both in the oral mucosa and in skin in general (30-33). 
This study had several limitations that need to be addressed. One limitation is the limited number of clinical cases available for investigation. In addition, it can be difficult to associate the present in vitro results with the in vivo mechanisms responsible for the complex wound healing processes initiated after surgical placement of the xenogeneic collagen matrix. Another drawback is that the present results are based on a short 5-day incubation period. More studies involving larger groups of patients and longer incubation times of the collagen matrix are needed to better expand and explain the present findings.

In conclusion, the interaction between $\mathrm{T}$ cells and the 3D collagen matrix did not impair the healing process, it may accelerate oral wound healing following surgery, and increase the activity of immune system cells. However, these results need further research to fully explore the implications of the interactions between the resorbable 3D collagen matrix used for oral soft tissue regeneration and the T cells.

\section{Acknowledgements}

Not applicable.

\section{Funding}

This study was partially supported by internal grants from the 'Victor Babes' University of Medicine and Pharmacy, Timisoara, Romania: DUROTOM-P-IV-CI-PDCC 2015/2016, contract 7199/01.07.2015 and DENTALOCT PIII-C2PCFI 2015/2016. The manuscript was reviewed by native English-speaking experts from BioMed Proofreading, LLC (Cleveland, OH, USA).

\section{Availability of data and materials}

The datasets used and/or analyzed during the current study are available from the corresponding author on reasonable request.

\section{Authors' contributions}

RD, SIS, RS and SP participated in study design and sample collection, as well as in acquisition of data. BF and PV performed cell analysis of T-lymphocytes and aquisition of data. MB drafted the manuscript and revised it critically for intellectual content. CB, CC and DA carried out data analysis and statistical analysis. MS and $\mathrm{CH}$ contributed to data acquisition and drafting the manuscript. AR and NPG contributed to the design and critical revision of the study. $\mathrm{RD}, \mathrm{CH}$ and MS contributed equally to this study and can be considered first authors. All authors read and approved the final version of manuscript.

\section{Ethics approval and consent to participate}

The protocol and patient informed consent process were approved by the Commission of Research Ethics of the 'Victor Babes' University of Medicine and Pharmacy (06/27.06.2013; Timisoara, Romania). Written informed consent was obtained from all the patients.

\section{Patient consent for publication}

Not applicable.

\section{Competing interests}

The authors declare that they have no competing interests.

\section{References}

1. Nevins M, Nevins ML, Kim SW, Schupbach P and Kim DM: The use of mucograft collagen matrix to augment the zone of keratinized tissue around teeth: A pilot study. Int J Periodontics Restorative Dent 31: 367-373, 2011.

2. Lin GH, Chan HL and Wang HL: The significance of keratinized mucosa on implant health: A systematic review. J Periodontol 84: 1755-1767, 2013.

3. Hall WB and Lundergan WP: Free gingival grafts. Current indications and techniques. Dent Clin North Am 37: 227-242, 1993.

4. Tonetti MS and Jepsen S; Working Group 2 of the European Workshop on Periodontology: Clinical efficacy of periodontal plastic surgery procedures: Consensus report of Group 2 of the 10th European Workshop on Periodontology. J Clin Periodontol 41 (Suppl 15): S36-S43, 2014.

5. Zuhr O, Bäumer D and Hürzeler M: The addition of soft tissue replacement grafts in plastic periodontal and implant surgery: Critical elements in design and execution. J Clin Periodontol 41 (Suppl 15): S123-S142, 2014.

6. Scarano A, Barros RR, Iezzi G, Piattelli A and Novaes AB Jr: Acellular dermal matrix graft for gingival augmentation: A preliminary clinical, histologic, and ultrastructural evaluation. J Periodontol 80: 253-259, 2009.

7. McGuire MK, Scheyer ET, Nunn ME and Lavin PT: A pilot study to evaluate a tissue-engineered bilayered cell therapy as an alternative to tissue from the palate. J Periodontol 79: 1847-1856, 2008.

8. Sanz M, Lorenzo R, Aranda JJ, Martin C and Orsini M: Clinical evaluation of a new collagen matrix (Mucograft prototype) to enhance the width of keratinized tissue in patients with fixed prosthetic restorations: A randomized prospective clinical trial. J Clin Periodontol 36: 868-876, 2009.

9. McGuire MK and Scheyer ET: Randomized, controlled clinical trial to evaluate a xenogeneic collagen matrix as an alternative to free gingival grafting for oral soft tissue augmentation. J Periodontol 85: 1333-1341, 2014.

10. Teller P and White TK: The physiology of wound healing: Injury through maturation. Surg Clin North Am 89: 599-610, 2009.

11. Portou MJ, Baker D, Abraham D and Tsui J: The innate immune system, Toll-like receptors and dermal wound healing: A review. Vascul Pharmacol 71: 31-36, 2015.

12. Dasu MR and Isseroff RR: Toll-like receptors in wound healing: Location, accessibility, and timing. J Invest Dermatol 132: 1955-1958, 2012.

13. Sorg H, Tilkorn DJ, Hager S, Hauser J and Mirastschijski U: Skin wound healing: An update on the current knowledge and concepts. Eur Surg Res 58: 81-94, 2017.

14. Sun BK, Siprashvili Z and Khavari PA: Advances in skin grafting and treatment of cutaneous wounds. Science 346 : 941-945, 2014.

15. Rusu D, Stratul SI, Festila D, Surlin P, Kasaj A, Baderca F, Boariu M, Jentsch H, Locovei C and Calenic B: Histology and surface ultrastructure during early healing after gingival augmentation with a three-dimensional collagen matrix: A report of six cases. Quintessence Int 48: 57-67, 2017.

16. Martin P and Nunan R: Cellular and molecular mechanisms of repair in acute and chronic wound healing. Br J Dermatol 173: 370-378, 2015

17. Kabashima K (ed): Basic and clinical sciences in skin immune responses. In: Immunology of the Skin. 1st edition. Springer Japan, pp95-111, 2016.

18. Zhang C, Xiao C, Dang E, Cao J, Zhu Z, Fu M, Yao X, Liu Y, Jin B, Wang G, et al: CD100-Plexin-B2 promotes the inflammation in psoriasis by activating NF- $\mathrm{KB}$ and inflammasome in keratinocytes. J Invest Dermatol 138: 375-383, 2018.

19. Chen L and Flies DB: Molecular mechanisms of T cell co-stimulation and co-inhibition. Nat Rev Immunol 13: 227-242, 2013. 
20. Sena LA, Li S, Jairaman A, Prakriya M, Ezponda T, Hildeman DA, Wang CR, Schumacker PT, Licht JD, Perlman H, et al: Mitochondria are required for antigen-specific $\mathrm{T}$ cell activation through reactive oxygen species signaling. Immunity 38 : 225-236, 2013.

21. Mackay LK, Braun A, Macleod BL, Collins N, Tebartz C, Bedoui S, Carbone FR and Gebhardt T: Cutting edge: CD69 interference with sphingosine-1-phosphate receptor function regulates peripheral T cell retention. J Immunol 194: 2059-2063, 2015.

22. Etich J, Bergmeier V, Frie C, Kreft S, Bengestrate L, Eming S, Mauch C, Eckes B, Ulus H, Lund FE, et al: PECAM1(+)/Sca1(+)/ CD38(+) vascular cells transform into myofibroblast-like cells in skin wound repair. PLoS One 8: e53262, 2013.

23. De Obaldia ME and Bhandoola A: Transcriptional regulation of innate and adaptive lymphocyte lineages. Annu Rev Immunol 33 607-642, 2015 .

24. Chen L, Mehta ND, Zhao Y and DiPietro LA: Absence of CD4 or CD8 lymphocytes changes infiltration of inflammatory cells and profiles of cytokine expression in skin wounds, but does not impair healing. Exp Dermatol 23: 189-194, 2014.

25. Nosbaum A, Prevel N, Truong HA, Mehta P, Ettinger M, Scharschmidt TC, Ali NH, Pauli ML, Abbas AK and Rosenblum MD: Cutting edge: Regulatory T cells facilitate cutaneous wound healing. J Immunol 196: 2010-2014, 2016.

26. Sugimoto MA, Vago JP, Teixeira MM and Sousa LP: Annexin A1 and the resolution of inflammation: Modulation of neutrophil recruitment, apoptosis, and clearance. J Immunol Res 2016 : 8239258, 2016. doi: 10.1155/2016/8239258.
27. Yeh SH, Kong FL and Lin MH: Visualization of apoptosis: Annexin V imaging. In: Personalized Pathway-Activated Systems Imaging in Oncology. Inoue T, Yang D and Huang G (eds). Springer, Singapore, pp233-243, 2017

28. Pietkiewicz S, Schmidt JH and Lavrik IN: Quantification of apoptosis and necroptosis at the single cell level by a combination of imaging flow cytometry with classical Annexin V/propidium iodide staining. J Immunol Methods 423: 99-103, 2015.

29. Weyd H, Abeler-Dörner L, Linke B, Mahr A, Jahndel V, Pfrang S, Schnölzer M, Falk CS and Krammer PH: Annexin A1 on the surface of early apoptotic cells suppresses $\mathrm{CD} 8^{+} \mathrm{T}$ cell immunity. PLoS One 8: e62449, 2013.

30. Boda D: Cellomics as integrative omics for cancer. Curr Proteomics 10: 237-245, 2013.

31. Caruntu C, Boda D, Constantin C, Caruntu A and Neagu M: Catecholamines increase in vitro proliferation of murine B16F10 melanoma cells. Acta Endocrinol (Copenh) 10: 545-558, 2014.

32. Lupu M, Caruntu A, Caruntu C, Papagheorghe LM, Ilie MA, Voiculescu V, Boda D, Constantin C, Tanase C, Sifaki M, et al: Neuroendocrine factors: The missing link in non-melanoma skin cancer (Review). Oncol Rep 38: 1327-1340, 2017.

33. Ion A, Popa IM, Papagheorghe LM, Lisievici C, Lupu M, Voiculescu V, Caruntu C and Boda D: Proteomic approaches to biomarker discovery in cutaneous T-cell lymphoma. Dis Markers 2016: 9602472, 2016. doi: 10.1155/2016/9602472. International (CC BY-NC-ND 4.0) License. 